\title{
A Research on Reading Therapy of Chinese University Students with Depression
}

\author{
Yang Hua \\ Scientific and Technical Information Institute, Jiangsu University, Zhenjiang, China \\ 497968074@qq.com
}

\begin{abstract}
This paper discusses the treatment of Chinese university students with depression by reading therapy, and provides theoretical and experimental basis for improving university students' depression. In this study, Beck Depression Inventory was used to measure the psychology of university students to discover depressed university students and evaluate the effect of reading therapy experiment. The researcher observed the effect of reading professional psychological books and general recreational books on university students' depression, and compared the two kinds of effects. Reading therapy has a significant effect on improving the psychological problems of Chinese university students with depression. General recreational reading is more effective in the treatment of university students depression than professional psychological reading.
\end{abstract}

Keywords: Reading Therapy; University Students; Depression

\section{Introduction}

Nowadays, university students, as a special group of Chinese society, represent advanced culture, are the pillars of social progress and are under unprecedented pressure. They are young and energetic, but lack social experience and are emotionally fragile, unable to fully understand and position themselves. They bear the pressure of various aspects inside and outside the school, such as study, examination, employment, interpersonal communication, love, etc., some students have inferiority complex, loneliness and unclear life goals. Therefore, during the study period, university students will inevitably have psychological problems, especially depressive symptoms, and this proportion shows an increasing trend year by year.

Therefore, mental health education is an important work of Chinese universities. However, due to the lack of education resources of mental health in Chinese universities at present, universities have not carried out sufficient publicity for students, which leads to some students' insufficient understanding of mental health problems and their belief that psychological problems such as depression are shameful. At the same time, students with depression worry about privacy exposure, fear of being discriminated against by other students, more dare not get legitimate help, and then gradually aggravate the degree of depression, forming a vicious circle, and even lead to suicide in serious cases (Xiao Yongchun, 2005:50) (Lin Lin, 2008: 643). Therefore, how to help university students to maintain and improve their mental health and treat depression and other psychological diseases has become an urgent problem for Chinese and universities to solve in combination with the development of Chinese society and the characteristics of university students, and has attracted extensive attention from all sectors of society.

Reading Therapy comes from Greek and is also called book therapy. Based on the principles of medicine, nursing, physiology, reader psychology, sociology and pedagogy, reading therapy selects targeted reading materials and conducts guided reading for readers, so as to alleviate or eliminate the psychological troubles and obstacles of readers。Reading therapy improves readers' mood and psychological state through reading, and makes appropriate adjustments to their behavior patterns, so as to improve the quality of life, study and work efficiency, so as to benefit readers' physical and mental health。The study found that reading therapy can further stimulate a series of psychological effects of reading by strengthening reading and encouraging readers to think, so as to achieve the prevention, relief and even treatment of psychological diseases (Liu Zhibin, 2014:69).。 Reading therapy has the advantages of relatively simple treatment procedure, low cost, easy to accept and obvious efficacy. Therefore, it can be one of the effective methods to prevent and treat depression。

\section{Comprehensive Analysis of the Research}

\subsection{Reading Therapy Place of University Students is the Library}

The university library is the document data information center of the university. The seminar on basic theories of library science in China stated that "disseminating knowledge and benefiting mankind" is the core value of libraries. This is also the core value of the university library, and the education function of "disseminating knowledge" can only be fully reflected in the university library. Professor Wu Weici once 
summarized the education task of the university library into nine key points and emphasized four functions (Wu Weizi, 2002:102). He said: "the function of ideological and moral education for students, the function of professional education for teaching, the function of expanding students' knowledge, the function of quality education, the function of providing method guidance for users using literature and modern technical means, the function of bibliography education and information education." The education function of university library is not only for the whole teachers, but also for students. It can be said that it is both an educational service and a service education. The education function of university library is mainly realized through reading. The function and value of libraries are mainly reflected by the reading activities of users. In other words, modern libraries are specialized social facilities for people to read (Chen Wangheng. 2007:367). It can be seen that the university library will become a miniature of "reading society".It is in the deep feeling of readers that the existence of the library has a higher value, and the library has changed from a building into a life.

It can be said that the university library is the best place to develop reading therapy. First of all, the university library is the department that has the most contact with students. With such advantaged and convenient conditions, it is the obligatory duty of university libraries to carry out targeted reading therapy to solve the psychological problems of university students. Secondly, reading activities are the network of interaction among "reader-book-environment", which is not only a closed system between readers and reading materials, but also an open system between readers and the environment. Reading cannot be generated and developed in isolation beyond the environment, so we must pay more attention to the reading environment. Reading environment generally refers to the sum of all external forces that affect readers' reading. It is composed of the whole surrounding things and is a three-dimensional and multi-level subsystem. The university library has spacious and bright reading room, playing relaxing and relaxing light music, sitting in such an environment to read their favorite books, is really a kind of enjoyment. German classical philosopher Schelling said: "Architecture is frozen music."'Music is a flowing architecture." German musician Prdman said, Indeed, when people are in and walking through the library complex, the space created between the buildings is constantly fluctuating, flowing, changing, and so on, which really gives people an exciting sense of melody (Gong Meiling, 2004:95) Furthermore, university libraries not only have clearly classified books and periodicals, but also subject librarians with multi-disciplinary knowledge of psychology, pedagogy, sociology, library science and so on. On the premise of protecting the privacy of university students' reading, they can answer the students' consultation, prescribe appropriate medicine to the case and make a list of books to read. University students taking "book medicine" in the library have the following advantages: "first, strong confidentiality, no harm to self-esteem. Second, it is economical, convenient and timely. Third, reading therapy can make up for the shortage of psychologists (Wang Bo, 2004:47)." Finally, the university library has the most advanced modern network information technology. We must carry out online reading therapy consultation station, so that online green reading and reading therapy in the place can be carried out simultaneously, so as to solve the psychological problems of university students more effectively.

\subsection{Interactive Reading Therapy is More Effective for University Students}

Although traditional Chinese people prefer reading therapy as a method of self-healing rather than as a method of other-healing. However, interactive reading therapy with the participation of reading therapists can achieve better therapeutic effects. Interactive reading therapy emphasizes contacting readers, intervening and managing readers' reading in the whole process, and adopting various ways to ensure readers' reading efficiency. Interactive reading therapy, which treats reading as a therapeutic art rather than a form of re-education, has the advantage of improving therapeutic relationships. Wayward Paddington, the mother of reading therapy in the UK, has repeatedly stressed that spending time talking to readers is an interactive reading therapy to discover their interests and encourage them to read further. It can be seen that interactive reading therapy is a trinity of participants, literatures and instructors, which means double interaction is conducive to the production of miraculous effects. Reading about therapeutic drugs is literature. There is a famous formula for reading therapy: choose the right books + psychological guidance + health care, therapeutic goals $=$ reading therapy. The proper process is to select books and list them, just as a doctor prescribes a prescription for a routine treatment.

\subsection{Reading Therapy Staff of University Students}

Reading therapy staff should master "general psychological counseling knowledge", "certain literary literacy" and "multiple knowledge structure", but also must have modesty, integrity, honesty, magnanimity, 
amiable, approachable personality conditions. Although at present, the human resource structure of Chinese university libraries is not ideal, lacking medical and psychological professionals. However, libraries should be fully qualified to carry out basic reading therapy. Because by virtue of the knowledge structure of library science, information science and other disciplines, and at the same time, librarians can give full play to their tacit knowledge, they can meet the challenges of reading guidance and other work. If the organizer wants to further develop the reading therapy in universities, it needs to integrate the human resource structure. The specific strategies can be divided into internal and external categories. The strategy of personnel internal integration is the process of realizing the organizational efficiency and goal through the local adjustment and allocation of the existing professional and technical personnel in the library, paying attention to the development of internal human resources. In recent years, the composite service mode is the main service mode of many university libraries. Under the support of digital information technology, Internet and LAN, the traditional phenomenon that staff focus on circulation and reading departments has been changed, and it is relatively easy to adjust and equip library staff. The strategy of personnel external integration is the personnel integration within the university and outside the library, or the personnel integration between different units outside the university. For example, full-time psychological counseling teachers in universities, professional doctors in hospitals and university libraries cooperate to carry out reading therapy, so as to give full play to their professional advantages and enhance their core competitiveness.

\section{The Concrete Practice of Research}

Researcher conducted a comprehensive reading therapy for university students with depression for 3 months in a university library in China, aiming to provide practical basis for the study of reading therapy in the treatment of university students with depression.

\subsection{Experimental Objects and Methods}

\subsubsection{Experimental Objects}

A total of 102 students from a certain university were recruited, and Beck Depression Inventory was used to conduct a questionnaire survey with anonymous contact information. Seventy-five questionnaires were collected, with a rate of $73.53 \%$. There are 34 male students and 41 female students. The questionnaire survey showed that the scale score of 42 people was higher than 16 points, indicating that they were prone to psychological depression. The researcher screened out 36 students who volunteered to receive reading therapy, and finally identified them as the subjects of this experiment. The students were randomly divided into groups for specialized psychological reading and groups for general recreational reading, with 18 people in each group. There was no statistically significant difference between the two groups in terms of gender, age and education level $(\mathrm{P}>0.05)$.

\subsubsection{The Experimental Method}

Selection of reading lists. Literature review, questionnaire survey, case study, interview and field survey were used to collect data. The researcher selected 31 books as the recommended bibliography of reading therapy. The researcher also surveyed the recommended bibliography among university students and collected 343 questionnaires. Fifteen books were selected by the majority of students and were finally determined as reading therapy books, as shown in table 1.The books in table 1 are divided into professional psychological books and general recreational books.

Table 1. Reading Therapy for Depression of Chinese University Students

\begin{tabular}{|l|l|}
\hline Classification & Book Name \\
\hline $\begin{array}{l}\text { Specialized } \\
\text { psychological } \\
\text { reading }\end{array}$ & Antidepressant Prescription \\
\cline { 2 - 2 } & Leaving Depression \\
\cline { 2 - 2 } & Burns' New Emotional Therapy \\
\cline { 2 - 2 } & Out of Depression \\
\cline { 2 - 2 } & Fantastic Psychological Hints for Yourself \\
\cline { 2 - 2 } & The Art of Peace \\
\hline \multirow{4}{*}{$\begin{array}{l}\text { General } \\
\text { recreational } \\
\text { reading }\end{array}$} & Everyone Can Succeed \\
\cline { 2 - 2 } & The Daffodil Has Gone by Carp \\
\cline { 2 - 2 } & Your Heart is Soft but Powerful \\
\cline { 2 - 2 } & Extreme Life \\
\hline
\end{tabular}




\begin{tabular}{|l|l|}
\hline \multirow{4}{*}{} & Blessing \\
\cline { 2 - 2 } & Alive \\
\cline { 2 - 2 } & Graduation from Peking University is Equal to Zero \\
\cline { 2 - 2 } & A Letter from a Strange Woman \\
\cline { 2 - 2 } & I Dedicate My Youth to You \\
\hline
\end{tabular}

Concrete implementation. The practice of reading therapy is mainly interactive reading therapy, and the reading time is 3 months in total. Members of each group are required to read an average of one book a month. During this period, students conducted background interview analysis, reading therapy explanation, individual reading, group reading, discussion and communication, speech and listening, written experience and so on. The researcher strengthened the effect of reading therapy for university students through comprehensive activities, and assisted and guided students through QQ, telephone and other remote means according to the characteristics of each student object. The students completed Beck Depression Inventory before and after reading therapy, and compared the scores before and after reading to assess the effect of reading therapy.

The establishment of reading therapy network platform. In combination with the characteristics of fast communication speed, wide range and strong interactivity of the network, researcher have appropriately established the network platform of reading therapy, such as QQ group and WeChat of reading therapy students. On the one hand, it is helpful to strengthen the publicity and promotion of reading therapy, so that university students can understand and accept reading therapy more clearly and deeply. On the other hand, it can also be used as a platform for the implementation of reading therapy, which has higher privacy for readers and can assist traditional reading therapy to a certain extent.

Evaluation tools. Beck Depression Inventory for depression was used to quantitatively evaluate the depression of the subjects. Score standard: 0 10 points, normal.11 16 points, mild depressive tendency.17 21 points, mild depression.22 to 30 points, moderate depression.31-40 points, major depression. More than 40 points, extreme depression.

\subsubsection{Statistical Analysis}

SPSS software was used for statistical analysis. The results are expressed as the mean and the standard deviation. $\mathrm{T}$ test was used for comparison. $\mathrm{P}<0.05$ is considered statistically significant.

\subsubsection{The Implementation Model}

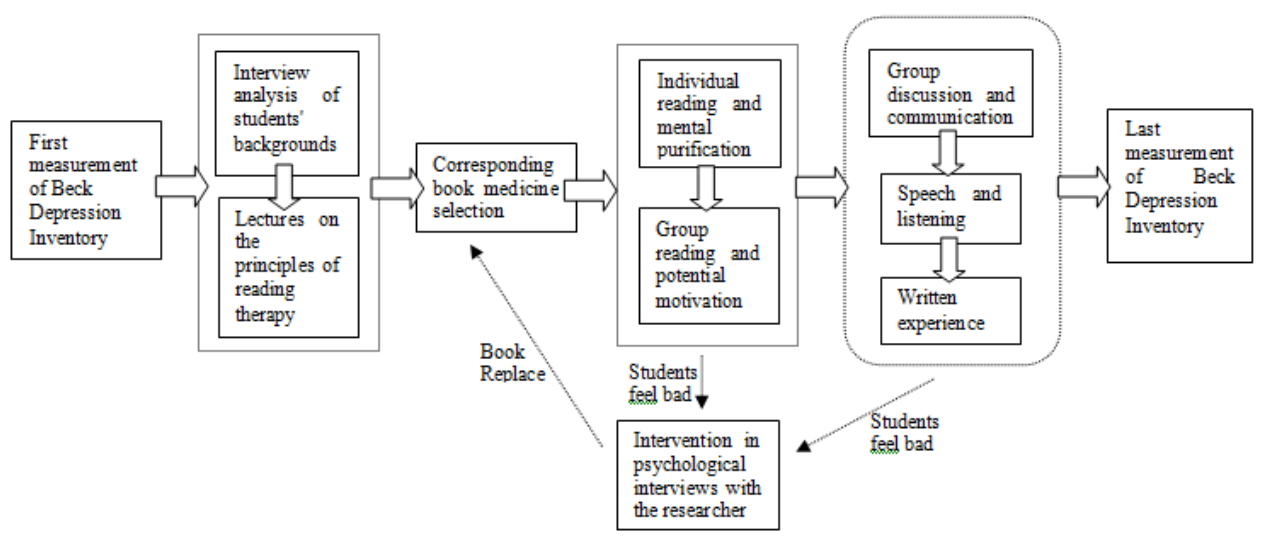

Figure 1. Implementation Model of Reading Therapy for University Students With Depression

\subsection{Results Analysis}

\subsubsection{Comparison of Depression Degree of University Students Before and After Experiment}

The degree of depression of university students before and after the experiment was quantitatively compared by Beck Depression Inventory. After the experiment, the number of university students with mild, moderate and severe depression decreased to different degrees than before the experiment. Eighteen of the students were reduced to normal and could be considered to be basically cured. The total cure rate was about $50 \%$, and that of the general recreational reading group was $61.11 \%$. By comparing the therapeutic effects 
of the professional psychological reading group and the general recreational reading group, the researcher found that the general recreational reading group had better therapeutic effects on university students' depression, $\mathrm{P}<0.05$, the difference was statistically significant. The specific data are shown in table 2 , table 3 and table 4 .

Table 2. Comparison of Depression Degree of Students Before and After Experiment

\begin{tabular}{|l|c|c|}
\hline $\begin{array}{c}\text { Degree of } \\
\text { depression }\end{array}$ & $\begin{array}{c}\text { Number of people } \\
\text { before the experiment }\end{array}$ & $\begin{array}{c}\text { Number of people } \\
\text { after the experiment }\end{array}$ \\
\hline Health & 0 & 18 \\
\hline Mild & 21 & 12 \\
\hline Moderate & 12 & 4 \\
\hline Severe & 3 & 2 \\
\hline
\end{tabular}

Table 3. Comparison of Depression Degree Between Two Groups Before and After Experiment

\begin{tabular}{|c|c|c|c|c|}
\hline \multirow[t]{2}{*}{$\begin{array}{l}\text { Degree of } \\
\text { depression }\end{array}$} & \multicolumn{2}{|c|}{$\begin{array}{c}\text { Professional psychological reading } \\
\text { group }\end{array}$} & \multicolumn{2}{|c|}{ General recreational reading group } \\
\hline & $\begin{array}{c}\text { Number of } \\
\text { people before the } \\
\text { experiment }\end{array}$ & $\begin{array}{l}\text { Number of } \\
\text { people after the } \\
\text { experiment }\end{array}$ & $\begin{array}{c}\text { Number of } \\
\text { people before } \\
\text { the experiment }\end{array}$ & $\begin{array}{l}\text { Number of people } \\
\text { after the experiment }\end{array}$ \\
\hline Health & 0 & 7 & 0 & 11 \\
\hline Mild & 10 & 6 & 11 & 6 \\
\hline Moderate & 6 & 3 & 6 & 1 \\
\hline Severe & 2 & 2 & 1 & 0 \\
\hline
\end{tabular}

Table 4. Comparison of Cure Rates Between Two Groups of Students After Experiment

\begin{tabular}{|l|c|c|}
\hline \multicolumn{1}{|c|}{ Categories of groups } & $\begin{array}{c}\text { Number of } \\
\text { people cured }\end{array}$ & $\begin{array}{c}\text { The cure rate } \\
(\%)\end{array}$ \\
\hline $\begin{array}{l}\text { Professional psychological } \\
\text { reading group }\end{array}$ & 7 & 38.89 \\
\hline $\begin{array}{l}\text { General recreational reading } \\
\text { group }\end{array}$ & 11 & 61.11 \\
\hline
\end{tabular}

\subsubsection{Data comparison of Beck Depression Inventory Scale Data Between two Groups Before and After Experiment}

Table 5 is the comparison of Beck Depression Inventory scale data before and after the experiment between two groups of students. After the experiment, Beck Depression Inventory scores of both groups were lower than before the experiment. The score of professional psychological reading group decreased slightly, while that of general recreational reading group decreased significantly. $\mathrm{P}<0.05$, both groups had statistically significant decreases in scores before and after the experiment. After the experiment, scores in the general recreational reading group dropped more than those in the other group, and the difference was statistically significant.

Table 5. Comparison of Beck Depression Inventory Scale Data Before and After Experiment

\begin{tabular}{|l|l|l|l|l|l|}
\hline \multirow{2}{*}{ Group } & \multicolumn{3}{|c|}{$\begin{array}{l}\text { Beck Depression Inventory } \\
\text { scale data }\end{array}$} & $\begin{array}{l}\text { Comparison of } \\
\text { before and after } \\
\text { experiment in } \\
\text { each group }\end{array}$ \\
\cline { 2 - 5 } & \multicolumn{2}{|c|}{ Before experiment } & \multicolumn{2}{c|}{ After experiment } & $\begin{array}{l}\text { Comparison } \\
\text { between two } \\
\text { groups }\end{array}$ \\
\hline $\begin{array}{l}\text { Professional } \\
\text { psychological } \\
\text { reading group }\end{array}$ & $21.13 \pm 4.52$ & $\begin{array}{l}\text { Comparison } \\
\text { between two } \\
\text { groups }\end{array}$ & $18.92 \pm 3.05$ \\
\hline
\end{tabular}




\begin{tabular}{|l|l|l|l|l|l|}
\hline $\begin{array}{l}\text { General } \\
\text { recreational } \\
\text { reading group }\end{array}$ & $21.22 \pm 4.11$ & $\mathrm{P}\rangle 0.05$ & $15.41 \pm 4.35$ & $\mathrm{P}\langle 0.05$ & $\mathrm{P}\langle 0.05$ \\
\hline
\end{tabular}

\section{Discussion and Conclusion}

The reading therapy of university students' depression psychology is an interdisciplinary subject involving medicine, library science and psychology. With the deepening of the research on reading therapy, its application objects can also be gradually expanded. From university students to various industries people in need of psychological help, more and more Chinese scholars are involved in the research on reading therapy, forming an independent research system.

Research practice shows that reading therapy is effective in improving university students' depression, with an overall improvement rate of 50\%.The general recreational reading group reached $61.11 \%$, much higher than the professional psychological reading group. The above results were also supported in the comparison of Beck Depression Inventory scores before and after reading. The scores of general recreational reading group were significantly lower than those before the experiment, while those of professional psychological reading group were not significantly lower. Compared with professional psychological reading materials, general recreational reading materials can arouse more resonance in students' hearts, and its effect on improving depression is better than that of professional psychological reading materials. This may be because professional psychological reading materials are more theoretical and have relatively profound contents, and the specific psychological mechanism needs to be further explored (Han Yingying, 2016:69). Therefore, the research results suggest that reading therapy should pay more attention to the selection of bibliography in the treatment of university students' depression. According to different causes of depression, reading therapy should also have different bibliographic prescriptions to achieve better therapeutic effects.

Reading therapy for university students with depression is a multidisciplinary interdisciplinary approach. Therefore, therapy first needs to set up a service team suitable for research and have relevant disciplinary background. For university students, the therapy service team should be composed of library staff, school psychological counselors, counselors and teachers, etc., and all members of the service team should receive relevant training such as reading therapy and mental health education. Secondly, in order to carry out reading therapy more effectively, reasonable selection of reading bibliography should be carried out. Reasonable bibliographic prescriptions will have higher selectivity and pertinence in the application process, so that readers can make better choices and obtain greater results (Gong Meiling, 2016:80). At the same time, the reading room for university students is different from the common place of library. When the bibliographic index of reading therapy is established, the university library can set up special areas for different psychological problems, which can be used as the index for the convenience of readers' classification. Thirdly, when carrying out the reading therapy for university students, the forms should also be diversified and conform to the development of the society and the actual situation of hardware conditions. Finally, in the implementation process, the university library should focus on the traditional reading therapy, with the appropriate network platform as the auxiliary, so that the reading therapy combines the traditional and the network two different forms (Wang Jinwen. 2015:65).

In addition, reading therapy associations can be established in universities. Through various activities, the association promotes more university students with psychological needs to participate in reading therapy. The university may hold reading activity competition, reading group discussion and other forms of activities, so that readers can benefit from the practice process, and is conducive to the extensive development and in-depth research of reading therapy. In the university curriculum, the elective course of reading therapy can be set up appropriately. Students choose courses according to their psychological needs, and teachers give lectures according to students' psychological needs and guide reading appropriately. The course can also set up appropriate reading activities for students' psychological problems as another way to help students solve their psychological problems. 
Chen Wangheng. (2007). Environmental Aesthetics. Wuchang: Wuhan University Press.

Gong Meiling. (2016). Analysis of Depression Disorder Reading Therapy for College Students Caused by Lovelorn Love. Beijing: Journal of university library.

Gong Meiling. (2004). Study on reading therapy for college students with psychological problems. Beijing: Journal of Chinese library.

Han Yingying. (2016). Study on the Intervention of Reading Therapy for Prisoners With Depression. Hei Longjiang: Library Construction.

Lin Lin. (2008). The Present Situation and Countermeasures of College Students' Mental Health. Beijing:Chinese School Hygiene.

Liu Zhibin. (2014). On the Advantages and Strategies of Reading Therapy in the Psychological Reconstruction of Post-disaster Adolescents. Beijing: National library Journal.

Wang Bo. (2004). Types of Reading Therapy. Beijing: Journal of university library.

Wang Jinwen. (2015). Research on the Construction of Chinese Online Reading Therapy Platform Based on Website Survey. Jinan: Journal of Shandong Library.

Wu Weizi. (2002). Library Science Introduction. Beijing: Beijing library Press.

Xiao Yongchun. (2005). Analysis on the Present Situation of College Students' Mental Health Quality. Shanghai: Fudan University Education Discussion. 